\title{
Local delivery of controlled-release simvastatin/ PLGA/HAp microspheres enhances bone repair
}

This article was published in the following Dove Press journal:

International Journal of Nanomedicine

10 October 2013

Number of times this article has been viewed

\author{
I-Chun Tai ${ }^{1-3}$ \\ Yin-Chih Fu ${ }^{3,4}$ \\ Chih-Kuang Wang ${ }^{3,5}$ \\ Je-Ken Chang $g^{3,4,6}$ \\ Mei-Ling $\mathrm{Ho}^{1-3}$ \\ 'Graduate Institute of Medicine, \\ 2Department of Physiology, \\ ${ }^{3}$ Orthopedic Research Center, \\ College of Medicine, ${ }^{4}$ Department \\ of Orthopedics, ${ }^{5}$ Department of \\ Medicinal and Applied Chemistry, \\ College of Life Science, Kaohsiung \\ Medical University, ${ }^{6}$ Department of \\ Orthopedics, Kaohsiung Municipal \\ Ta-Tung Hospital, Kaohsiung, Taiwan
}

Correspondence: Mei-Ling Ho

Department of Physiology, Orthopedic Research Center, College of Medicine,

Kaohsiung Medical University, 100 Shih-

Chuan Ist Road, Kaohsiung 807,

Taiwan

Tel +8867312 II 01 ext 2309

$\mathrm{Fax}+88673234687$

Email homelin@cc.kmu.edu.tw

\begin{abstract}
Statins are used clinically for reduction of cholesterol synthesis to prevent cardiovascular disease. Previous in vitro and in vivo studies have shown that statins stimulate bone formation. However, orally administered statins may be degraded during first-pass metabolism in the liver. This study aimed to prevent this degradation by developing a locally administered formulation of simvastatin that is encapsulated in poly(lactic-co-glycolic acid)/hydroxyapatite (SIM/PLGA/HAp) microspheres with controlled-release properties. The effect of this formulation of simvastatin on bone repair was tested using a mouse model of gap fracture bridging with a graft of necrotic bone. The simvastatin released over 12 days from $3 \mathrm{mg}$ and $5 \mathrm{mg}$ of SIM/PLGA/ HAp was $0.03-1.6 \mu \mathrm{g} /$ day and $0.05-2.6 \mu \mathrm{g}$ /day, respectively. SIM/PLGA/HAp significantly stimulated callus formation around the repaired area and increased neovascularization and cell ingrowth in the grafted necrotic bone at week 2 after surgery. At week 4, both $3 \mathrm{mg}$ and $5 \mathrm{mg}$ of SIM/PLGA/HAp increased neovascularization, but only $5 \mathrm{mg}$ SIM/PLGA/HAp enhanced cell ingrowth into the necrotic bone. The low dose of simvastatin released from SIM/PLGA/HAp enhanced initial callus formation, neovascularization, and cell ingrowth in the grafted bone, indicating that SIM/PLGA/HAp facilitates bone regeneration. We suggest that SIM/PLGA/ HAp should be developed as an osteoinductive agent to treat osteonecrosis or in combination with an osteoconductive scaffold to treat severe bone defects.
\end{abstract}

Keywords: statin, controlled release, poly(lactic-co-glycolic acid), microspheres, bone fracture

\section{Introduction}

Most bone fractures can be spontaneously repaired; however, each year in the United States, approximately $10 \%$ of fractures show delayed union or nonunion, ${ }^{1}$ resulting in enormous medical costs and lost productivity. ${ }^{2}$ The bone healing process involves cellular components, including osteoblasts, stem cells, and growth factors, such as vascular endothelial growth factor and bone morphogenetic protein-2 (BMP-2) ${ }^{3-5}$ BMP-2 has been used to enhance bone repair, but is costly. ${ }^{5}$ A high initial dose of BMP-2 has been observed to cause inflammation as a side effect. ${ }^{6}$ Therefore, identification of nonprotein small molecules to stimulate fracture healing is our research goal.

Simvastatin, a 3-hydroxy-3-methylglutaryl coenzyme A reductase inhibitor, has been used clinically to reduce blood cholesterol levels. ${ }^{7,8}$ Mundy et al demonstrated that statins stimulate BMP-2 gene expression in osteoblasts. ${ }^{9}$ Several in vitro studies further indicate that statins increase expression of osteogenic marker genes other than BMP-2, including Runt-related transcription factor 2 (RUNX-2), osteocalcin, osteopontin, and alkaline phosphatase, in osteoblastic cells and bone 
marrow-derived cells. ${ }^{10-15}$ Previous in vivo studies showed that oral administration of a high dose of simvastatin (20 mg/kg/day) enhances trabecular bone volume in ovariectomized rats. ${ }^{9,16}$ Skoglund et al also reported that systemic administration of an extremely high dose of simvastatin (120 mg/kg/day) in mice increases bone healing. ${ }^{17}$ Therefore, several studies have proposed that a systemically administered statin has beneficial effects on bone. ${ }^{15,18}$ In contrast, local delivery of statins has been reported to have a positive effect on bone formation. ${ }^{5,19-26}$ Mukozawa et al reported that simvastin with hydrogel and atelocollagen sponge (ACS) implants enhanced critical-sized nasal defects in rabbits. ${ }^{25}$ Ezirganli et al also indicated that local application of simvastatin enhanced healing of criticalsized bone defects in diabetic rats. ${ }^{26}$ However, some studies demonstrated that local delivery of statins without control of the optimal release concentration induces an inflammatory response. ${ }^{21,24,27}$ Therefore, this study aimed to develop a suitable carrier for controlling the release of simvastatin in an effective and nontoxic concentration range over a time duration that is appropriate to enhance bone healing.

Poly(lactic-co-glycolic acid) (PLGA) is considered a promising drug carrier due to its excellent biocompatibility and biodegradability. Although its degradation rate is altered by the ratio of poly(lactic acid) and poly(glycolic acid), our previous research found that adding hydroxyapatite (HAp) to PLGA can adjust the drug release profile and the $\mathrm{pH}$ value. ${ }^{28}$ Based on this concept, our previous study demonstrated that a controlled-released PLGA/HAp carrier releases the optimal concentration of recombinant human BMP-2 and improves new bone formation in a bone repair animal model. ${ }^{29}$ In this study, we fabricated a biodegradable carrier of PLGA/HAp to encapsulate simvastatin (SIM/PLGA/HAp) using a double emulsion method. We tested the osteogenic effects of SIM/ PLGA/HAp in mouse bone marrow mesenchymal stem cells and further tested its effects on bone repair using a mouse model of gap fracture bridging with a graft of necrotic bone, as in our earlier study. ${ }^{29}$

\section{Materials and methods}

\section{Preparation of simvastatin stock solution}

The simvastatin solution was prepared as described by Keyomarsi et al. ${ }^{30}$ Briefly, $40 \mathrm{mg}$ of simvastatin (Merck \& Company, Rahway, NJ, USA) was dissolved into $1 \mathrm{~mL}$ of ethanol and then mixed with $1.5 \mathrm{~mL}$ of $0.1 \mathrm{~N} \mathrm{NaOH}$. The simvastatin stock solution was heated at $50^{\circ} \mathrm{C}$ for 2 hours, and the $\mathrm{pH}$ was neutralized with $1 \mathrm{~N} \mathrm{HCl}$ ( $\mathrm{pH} 7.4$, Sigma-Aldrich, St Louis, MO, USA) to make a $10 \mathrm{mM}$ stock solution.

\section{Preparation and characterization of SIM/PLGA/HAp microspheres}

The microspheres were fabricated by the water-in-oil-inwater $(w / o / w)$ double emulsion technique modified from our previous method. ${ }^{29}$ Briefly, $16 \mathrm{mg}$ of HAp powder (Alfa Aesar ${ }^{\circledR}$, A Johnson Matthey Company, Ward Hill, MA, USA) was dissolved into phosphate-buffered saline to form the first water-phase solution. A $250 \mu \mathrm{L}$ sample of $10 \mathrm{mM}$ simvastatin stock solution and $5 \mathrm{mg}$ of Span 80 (Showa, Chemicals, Inc., Japan) were mixed with $10 \%$ PLGA50/50 (P2191, molecular weight 30,000-60,000, Sigma-Aldrich) in a dichloromethane solution (Reagent ACS, Fluka, Buchs, Switzerland) to form the oil phase. The first water-phase solution and the oil-phase solution were mixed and stirred at 1,000 rpm for 15 minutes to form the first water-in-oil (w/o) emulsion. The first emulsion (w/o) solution was added to $20 \mathrm{~mL}$ of the second water-phase solution along with 1\%(w/v) polyvinyl alcohol (PB-05, Chang Chun Petrochemical Co, Taipei, Taiwan) to form a second emulsion (w/o/w). The second w/o/w emulsion suspension was stirred at room temperature for 30 minutes to harden the microspheres. Suction was required to evaporate the dichloromethane during stirring and to solidify the microspheres. Finally, the microspheres were collected by centrifugation, washed with $0.1 \%$ polyvinyl alcohol three times, and lyophilized in a freeze dryer. The washing solution was evaluated for nonencapsulated simvastatin by high-pressure liquid chromatography (HPLC, Eclipse XDB-C18, Agilent Technologies, Santa Clara, CA, USA). The sample was filtered through a $0.45 \mathrm{~mm}$ syringe filter (Becton Dickinson and Company, Franklin Lakes, NJ, USA) to remove unwanted particulates, and the filtrate was then analyzed using the HPLC system. The percent encapsulation efficiency was calculated as being:

$$
=\frac{(\text { Mass of the total drug }- \text { Mass of free drug })}{\text { Mass of the total drug }} \times 100 \%
$$

and the percent encapsulation content as being:

$$
=\frac{(\text { Mass of the total drug }- \text { Mass of free drug })}{\text { Mass of microspheres }} \times 100 \% \text {. }
$$

The overall morphology of the microspheres was examined using scanning electron microscopy (JSM-5300, JEOL, Tokyo, Japan), and the mean diameter of the microspheres was calculated by dynamic light scattering particle size analysis (LS-230, Beckman Coulter, Fullerton, CA, USA). 


\section{Evaluation of release kinetics and monitoring $\mathrm{pH}$ in vitro}

Analysis of the release characteristics of SIM/PLGA/HAp was carried out according to the procedure outlined in a previous study. ${ }^{16}$ Briefly, $50 \mathrm{mg}$ of SIM/PLGA/HAp microspheres were resuspended in $5 \mathrm{~mL}$ of $\mathrm{pH} 7.4$ phosphatebuffered saline. These samples were positioned in a shaker with constant agitation at $60 \mathrm{rpm}$ and kept in an incubator at $37^{\circ} \mathrm{C}$. At predetermined time points $(1,2,3,4,5,6,7,9$, 11 , and 14 days), the samples were centrifuged, and $2.5 \mathrm{~mL}$ of the supernatant was withdrawn and replaced with $2.5 \mathrm{~mL}$ of fresh phosphate-buffered saline. The samples were then filtered through a $0.45 \mathrm{~mm}$ syringe filter, and HPLC analysis was conducted. The $\mathrm{pH}$ level of the buffer and the surface morphology of the microspheres were monitored.

\section{Cell culture}

Pluripotent mesenchymal cells (D1, American Type Culture Collection, Manassas, VA, USA), cloned from BALB/c mouse bone marrow cells, ${ }^{31}$ were maintained in bone medium (Dulbecco's Modified Eagle's Medium, Invitrogen, Carlsbad, CA, USA) containing $10 \%$ fetal bovine serum and $0.1 \%$ sodium ascorbate in a humidified atmosphere of 5\% carbon dioxide at $37^{\circ} \mathrm{C}$. Osteoinduction medium was used to induce osteogenic differentiation of D1 cells, which containing bone medium with $10 \mathrm{mM}$ beta-glycerophosphate (Sigma-Aldrich), $0.2 \mathrm{mM}$ L-ascorbic acid 2-phosphate (Sigma-Aldrich), and $100 \mathrm{mM}$ dexamethasone. Before drug treatment, the D1 cells were seeded in a culture well with $80 \%$ confluence.

\section{RNA extraction and real-time PCR}

Cells were seeded into a 6-well Transwell ${ }^{\mathrm{TM}}$ (Corning Costar, Corning, NY, USA) with a pore size of $0.8 \mu \mathrm{m}$ at a density of 500,000 cells/well. Next, $3 \mathrm{mg}$ (group A) and $5 \mathrm{mg}$ (group B) of SIM/PLGA/HAp microspheres were added to the wells for 3 days, and the cells were harvested on days 1,2, and 3 . Total RNA from the D1 cells was extracted by TRIzol reagent (Invitrogen). First-strand cDNA was synthesized from $1 \mu \mathrm{g}$ of total RNA using a High Capacity RNA-to-cDNA kit (Applied Biosystems, Bedford, MA, USA). Real-time polymerase chain reaction (PCR) was performed using an iQ5 real-time PCR detection system (Bio-Rad Laboratories Inc, Hercules, CA, USA) with SYBR Green Supermix (Applied Biosystems). Expression of osteogenic genes, BMP-2, alkaline phosphatase, RUNX-2, osteocalcin, and beta-actin was evaluated. The primers were designed as follows: BMP-2 forward 5'-AGCTGCAAGAGACACCCTTTG-3' and reverse 5'-AGCATGCCTTAGGGATTTTGGA-3'; alkaline phosphatase forward 5'-AACCCAGACAGCATTCC-3' and reverse 5'-GTCAGTCAGGTTGTTCCGATTCAA-3'; RUNX-2 forward 5'-CCCAGCCACCTTTACCTACA-3' and reverse 5'-TATGGAGTGCTGCTGGTCTG-3'; osteocalcin forward $5^{\prime}$-GAGGGCAATAAGGTAGTGAACA-3' and reverse 5'-AAGCCATACTGGTCTGATAGCTCG-3'; betaactin forward 5'-CCAACCGTGAAAAGATGACC-3' and reverse 5'-ACCAGAGGCATACAGGGACA-3'.

The PCR condition was $95^{\circ} \mathrm{C}$ for 30 seconds and $95^{\circ} \mathrm{C}$ for 4 minutes, followed by 40 cycles of $95^{\circ} \mathrm{C}$ for 10 seconds, $59^{\circ} \mathrm{C}$ for 15 seconds, and $72^{\circ} \mathrm{C}$ for 15 seconds. After the PCR reaction was complete, the melting curve was generated to confirm the specificity of the PCR reaction. Relative mRNA expression was calculated from the threshold cycle $(\mathrm{Ct})$ and normalized with beta-actin. Mean gene expression in the control group was assigned a value of one, and gene expression in each experimental group was calculated relative to the control. All real-time PCR experiments were performed in triplicate.

\section{Mineralization assay}

Alizarin red S staining was used to determine the level of calcification in the extracellular matrix. The cells were seeded into a 24-well Transwell at a density of 100,000 cells/well. The cells were treated with SIM/PLGA/HAp in culture medium for 3 days, and then replaced with osteoinduction medium for another 3 days. The cells were fixed in $10 \%$ formalin and phosphate-buffered saline for 10 minutes. After washing twice with double-distilled $\mathrm{H}_{2} \mathrm{O}$, the fixed cells were stained with Alizarin red S solution for 5 minutes. After staining, the cells were washed using double-distilled $\mathrm{H}_{2} \mathrm{O}$. The fixed and stained plates were then air-dried at room temperature. The amount of mineralization was determined by dissolving the cell-bound Alizarin red S in 10\% acetic acid and measurement at $415 \mathrm{~nm}$. The value was normalized to total protein in each well. The total protein in the cells was lysed in PhosphoSafe ${ }^{\mathrm{TM}}$ reagent (Novagen, Darmstadt, Germany). Protein concentrations were determined using the Bio-Rad protein assay (Bio-Rad Laboratories Inc). The detection wave length was $595 \mathrm{~nm}$.

\section{Tibia gap fracture graft with a necrotic bone model and SIM/PLGA/HAp}

All procedures were followed as in our previous study ${ }^{29}$ and in accordance with the specifications set down in the guidelines for animal experiments at Kaohsiung Medical University. Balb/C mice were anesthetized by an intraperitoneal $3.2 \mathrm{mg} / 30 \mathrm{~g}$ body weight injection of ketamine $\left(\right.$ Ketalar $^{\circledR}$, Parke-Davis, Taipei, Taiwan) in combination 
with $3.7 \mathrm{mg} / 30 \mathrm{~g}$ body weight of thiazine hydrochloride (Rompun $^{\circledR}$, Bayer HealthCare, Leverkusen, Germany). A $2 \mathrm{~mm}$ length of the middle shaft of the tibia on the right side of the mouse was cut out with a saw. The cut bone was frozen using liquid nitrogen for 5 minutes to serve as an avascular segment of necrotic bone graft. Next, the fragment was put back into the original site in the tibia and fixed by a syringe needle (No 26). The wound was sutured with 4-0 silk. The mice were divided into three groups, ie, group A (3 mg SIM/ PLGA/HAp microspheres), group B (5 mg SIM/PLGA/HAp microspheres), and a control group. The six mice in each experimental group were divided into two subgroups, ie, for observation until 2 or 4 weeks after surgery.

\section{Serum biochemistry}

Blood samples were obtained after the mice were sacrificed at the end of the 2-week or 4-week observation period for determination of liver enzymes (alanine aminotransferase and aspartate aminotransferase). A quantitative kinetic determination of serum creatinine was estimated using a kit from Stanbio Laboratory (Boerne, TX, USA).

\section{Soft X-ray observation}

At the end of week 2 or 4 after surgery, the operated tibia bone was radiographically examined by soft X-rays (Model M-100, SOFTEX, Tokyo, Japan) at $43 \mathrm{kVP}$ and $2 \mathrm{~mA}$ for 1.5 seconds. Appropriate magnification was used throughout the observation, and the results of the micrographs were compared between the groups, including the controls.

\section{Histological analysis and immunostaining of bone tissue}

Quantitative histochemical and immunohistochemical analyses were used to investigate the microscopic changes in bone tissue. Prior to hematoxylin-eosin and immunohistochemistry staining, all bone tissue samples were decalcified (0.5 M EDTA-2 $\mathrm{H}_{2} \mathrm{O}$ in double-distilled water $\left.[186.1 \mathrm{~g} / \mathrm{L}]\right)$, followed by fixation with $4 \%$ paraformaldehyde. These samples were embedded in paraffin wax, and $5 \mu \mathrm{m}$ sections were prepared. These sections were routinely stained with hematoxylin-eosin. At a magnification of $40 \times$, we defined the counted callus area as the $1 \mathrm{~mm}$ regions proximal and distal to the bone graft ends. The area of callus formation around the graft bone was measured using Image-Pro Plus 5.0 software (Media Cybernetics Inc, Rockville, MD, USA). The percentage of bone matrix within the callus was calculated and compared with that in the control group. At a magnification of $400 \times$, the numbers of stained cells within the necrotic bone were counted and compared between the samples and controls. Immunohistochemical staining for von Willebrand factor was performed. Sections were treated with $0.15 \mathrm{mg} / \mathrm{L}$ trypsin in phosphate buffer at $\mathrm{pH} 7.8$ for 9 minutes and then incubated overnight at $4^{\circ} \mathrm{C}$ with a $1: 300$ dilution of polyclonal rabbit antihuman von Willebrand factor antibody (Chemicon International Inc, Temecula, CA, USA). Goat antirabbit biotinylated immunoglobulin (DakoCytomation, Copenhagen, Denmark) was used at a 1:300 dilution as the secondary antibody at $37^{\circ} \mathrm{C}$ for 60 minutes. An avidin-biotinperoxidase complex kit (Vector Laboratories, Burlingame, CA, USA) was applied at a 1:300 dilution for 60 minutes at $37^{\circ} \mathrm{C}$. Peroxidase activity was detected by $0.4 \mathrm{mg} / \mathrm{L}$ of $3,3^{\prime}$-diaminobenzidine in phosphate buffer at $\mathrm{pH} 7.3$ in the presence of $0.12 \% \mathrm{H}_{2} \mathrm{O}_{2}$. Sections were then counterstained with hematoxylin. At a magnification of $400 \times$, the number of stained endothelial vessels within the necrotic bone was calculated and compared between the samples and controls.

\section{Statistical analysis}

Each experiment was repeated at least three times, and the data (expressed as the mean \pm standard error of the mean) from representative experiments are shown. Statistical significance was evaluated by one-way analysis of variance, and multiple comparisons were performed by Scheffe's method. $P<0.05$ was considered to be statistically significant.

\section{Results}

\section{Scanning electron microscopic observation and size of microspheres}

Scanning electron microscopic imaging of the SIM/PLGA/ HAp microspheres showed a smooth surface upon fabrication on day 0 (Figure 1A). During degradation, we found that the particle surface was rough and the microspheres shrank in size from day 7 to 14 to 21 . The particle size analysis data showed that approximately $85 \%$ of the fabricated microspheres were within the size range of $60-120 \mu \mathrm{m}$, and the average particle diameter was $117 \pm 25 \mu \mathrm{m}$ (Figure 1B).

\section{Evaluation of simvastatin encapsulation efficiency and release, and $\mathrm{pH}$}

The encapsulation content of simvastatin in SIM/PLGA/HAp was $0.34 \% \pm 0.04 \%$. The encapsulation efficiency of simvastatin in SIM/PLGA/HAp was $77.7 \% \pm 10.3 \%$. The in vitro release profile of simvastatin from SIM/PLGA/HAp in phosphate-buffered saline was analyzed by HPLC (Figure 2A). An initial burst release (0.53-0.24 $\mu \mathrm{g})$ was 


\section{A}

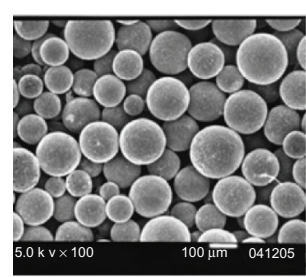

Day 0

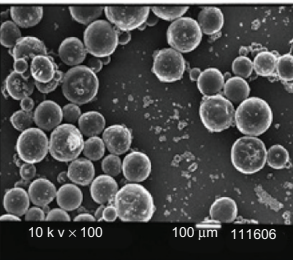

Day 7

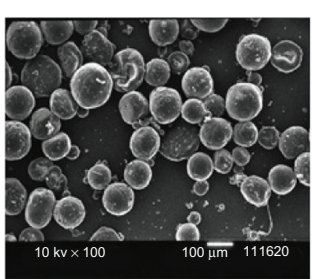

Day 14

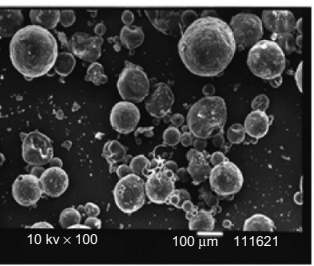

Day 21

B

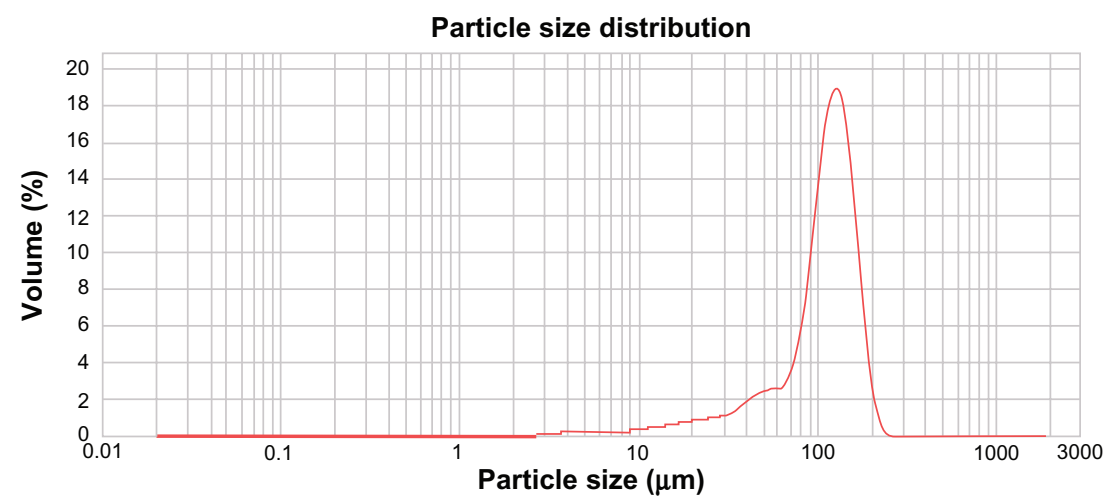

Figure I Physical properties of SIM/PLGA/HAp microspheres. (A) Scanning electron microscopic images of morphologic changes in SIM/PLGA/HAp at 0, 7, I4, and 2I days (100× magnification). (B) Particle size analysis data showing that the SIM/PLGA/HAp microspheres ranged between $60 \mu \mathrm{m}$ and $120 \mu \mathrm{m}$ in diameter. Abbreviation: SIM/PLGA/HAp, simvastatin encapsulated in poly(lactic-co-glycolic acid)/hydroxyapatite microspheres.

A

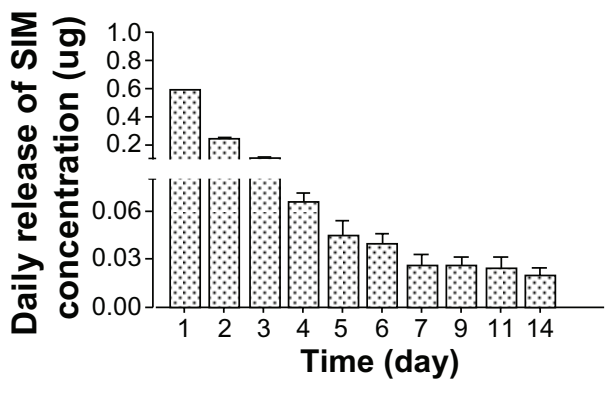

C

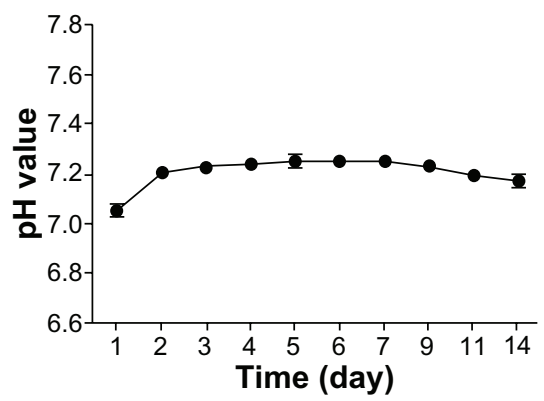

B

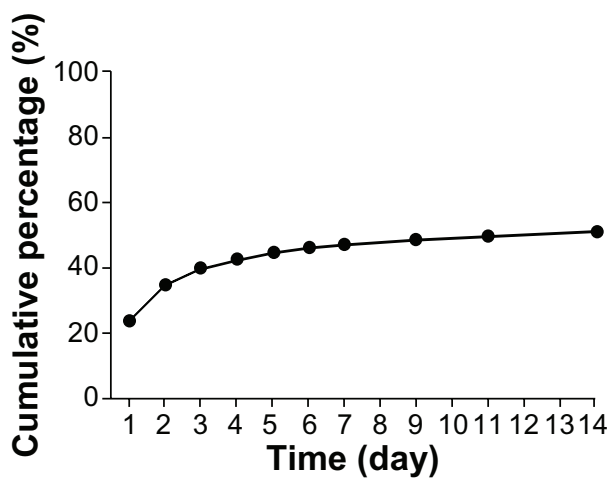

Figure 2 Simvastatin release profiles for SIM/PLGA/HAp microspheres and changes in $\mathrm{pH}$. (A) Daily release profile and (B) cumulative release profile for simvastatin measured by high-pressure liquid chromatography from $50 \mathrm{mg}$ SIM/PLGA/HAp into $50 \mathrm{~mL}$ phosphate-buffered saline at $37^{\circ} \mathrm{C}$ for 14 days. (C) $\mathrm{pH}$ was monitored each day.

Abbreviation: SIM/PLGA/HAp, simvastatin encapsulated in poly(lactic-co-glycolic acid)/hydroxyapatite microspheres. 

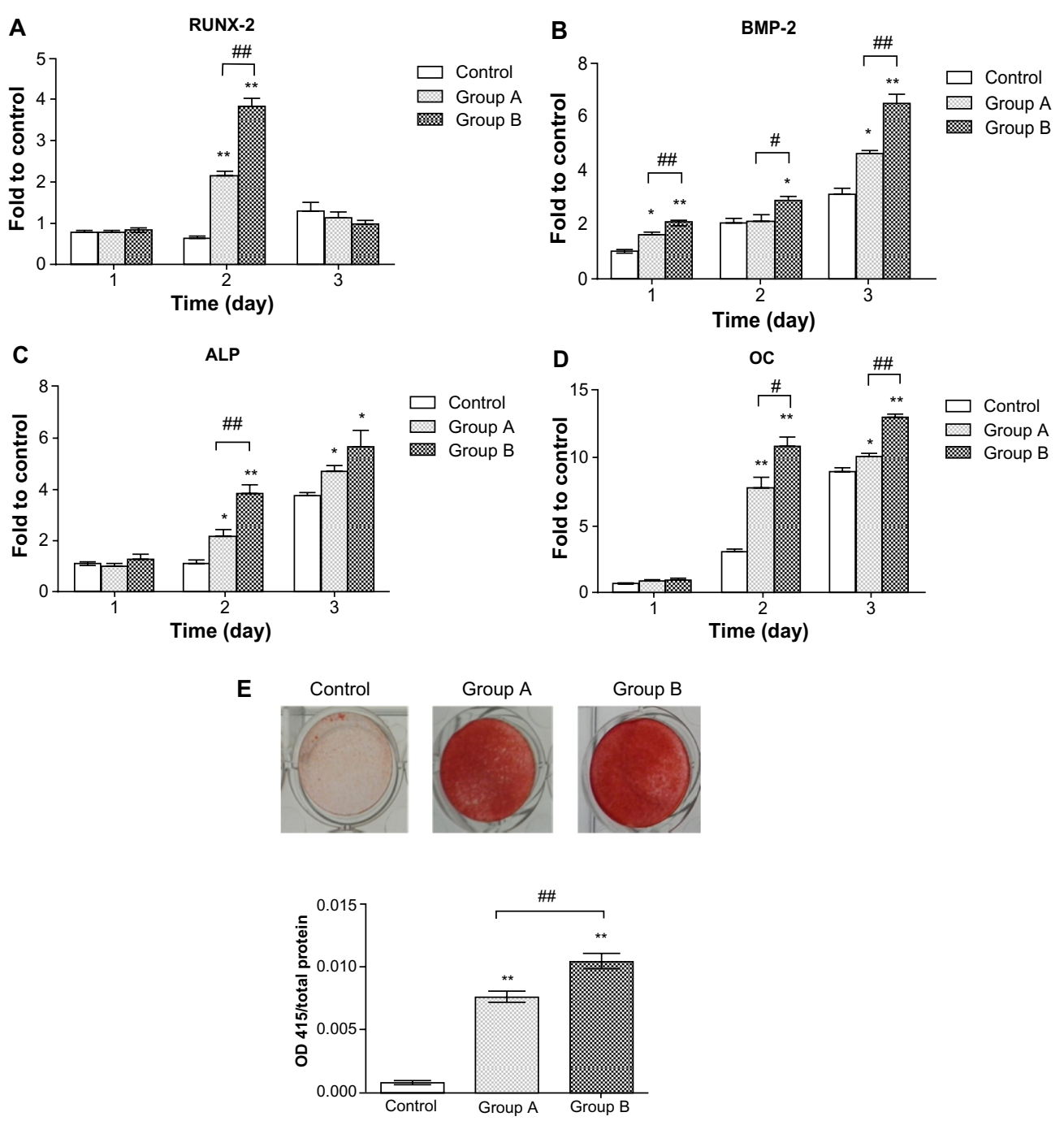

Figure 3 Effect of SIM/PLGA/HAp microspheres on osteogenic gene expression and mineralization in DI cells. Effects of SIM/PLGA/HAp microspheres on gene expression of (A) RUNX-2, (B) BMP-2, (C) alkaline phosphatase (ALP) (D) osteocalcin were determined by real-time polymerase chain reaction at days I, 2, and 3. All values were normalized to day I of the control group. (E) Representative wells from 24-well plates seeded with DI cells and stained with Alizarin red S after SIM/PLGA/HAp treatment for 3 days and cultivated in osteoinduction medium for another 3 days (group A, 3 mg SIM/PLGA/HAp; group B, 5 mg SIM/PLGA/HAp). *P $<0.05$; **P $<0.0$ I compared with control; ${ }^{\#}<0.05 ;{ }^{\# P}<0.0$ I between treatment groups.

Abbreviations: ALP, alkaline phosphatase; BMP-2, bone morphogenetic protein-2; RUNX-2, Runt-related transcription factor 2; OC, osteocalcin; SIM/PLGA/HAp, simvastatin encapsulated in poly(lactic-co-glycolic acid)/hydroxyapatite microspheres; OD, optical density.

found for the first 2 days, and the average daily release of simvastatin from the microspheres was consistent $(0.11-0.02 \mu \mathrm{g})$ for 12 days. The cumulative amount of simvastatin released was over $50 \%$ of the total concentration after 14 days of release (Figure 2B). Because the $\mathrm{pH}$ might change due to degradation of PLGA, we also monitored $\mathrm{pH}$ during degradation of the microspheres. The $\mathrm{pH}$ value remained in the range of 7.1-7.4 over 14 days (Figure 2C).

\section{Osteogenic effect of simvastatin released from SIM/PLGA/HAp microspheres}

The results of real-time PCR showed that RUNX-2 mRNA expression was significantly increased at day 2 in both treatment groups ( $P<0.01$, Figure $3 \mathrm{~A}$ ). BMP-2 expression was significantly elevated in group A on days 1 and $3(P<0.05)$ and in group B through days 1 to 3 ( $P<0.01$, Figure $3 \mathrm{~B})$. Expression of alkaline phosphatase and osteocalcin $(P<0.05$ and $P<0.01$, respectively) was also significantly higher on days 2 and 3 in both groups than in controls (Figure 3C and D). The quantitative results from Alizarin red staining show that the simvastatin released from the microspheres significantly enhanced mineralization in D1 cells. Further, the effect in group B was better than that in group A (Figure 3E).

\section{In vivo experiments}

\section{Serum biochemistry}

Serum biochemistry was investigated to determine the side effects of simvastatin released locally from SIM/PLGA/ 
Table I Measurements of liver and kidney enzymes in serum at 2 and 4 weeks after SIM/PLGA/HAp administration in Balb/C mice (group A, 3 mg SIM/PLGA/HAp; group B, 5 mg SIM/PLGA/HAp)

\begin{tabular}{cccr}
\hline & Control & Group A & Group B \\
\hline 2 weeks & & & \\
AST (U/L) & $84 \pm 18$ & $104 \pm 24$ & $101 \pm 28$ \\
ALT (U/L) & $43 \pm 8$ & $33 \pm 14$ & $47 \pm 13$ \\
CRE (U/L) & $0.7 \pm 0.1$ & $1.0 \pm 0.3$ & $0.6 \pm 0.1$ \\
4 weeks & & & \\
AST (U/L) & $130 \pm 7$ & $155 \pm 18$ & $173 \pm 60$ \\
ALT (U/L) & $66 \pm 34$ & $42 \pm 13$ & $86 \pm 23$ \\
CRE (U/L) & $0.7 \pm 0.2$ & $0.6 \pm 0.2$ & $0.6 \pm 0.1$ \\
\hline
\end{tabular}

Abbreviations: AST, aspartate aminotransferase; ALT, alanine aminotransferase; CRE, creatinine; SIM/PLGA/HAp, simvastatin encapsulated in poly(lactic-co-glycolic acid)/hydroxyapatite microspheres.

HAp with regard to the liver, muscle, and kidneys. At the end of 2 or 4 weeks of treatment, serum was harvested to measure liver and kidney enzymes (alanine aminotransferase, aspartate aminotransferase, and creatinine phosphokinase). No significant differences were observed between groups A and $\mathrm{B}$ or the control group, as shown in Table 1.

\section{Soft X-ray observation}

We applied SIM/PLGA/HAp to the bone defect model to observe the effect on bone repair in rats. Gross examination of bone union and callus formation was done using X-ray imaging (Figure 4). Large callus formation was found at weeks 2
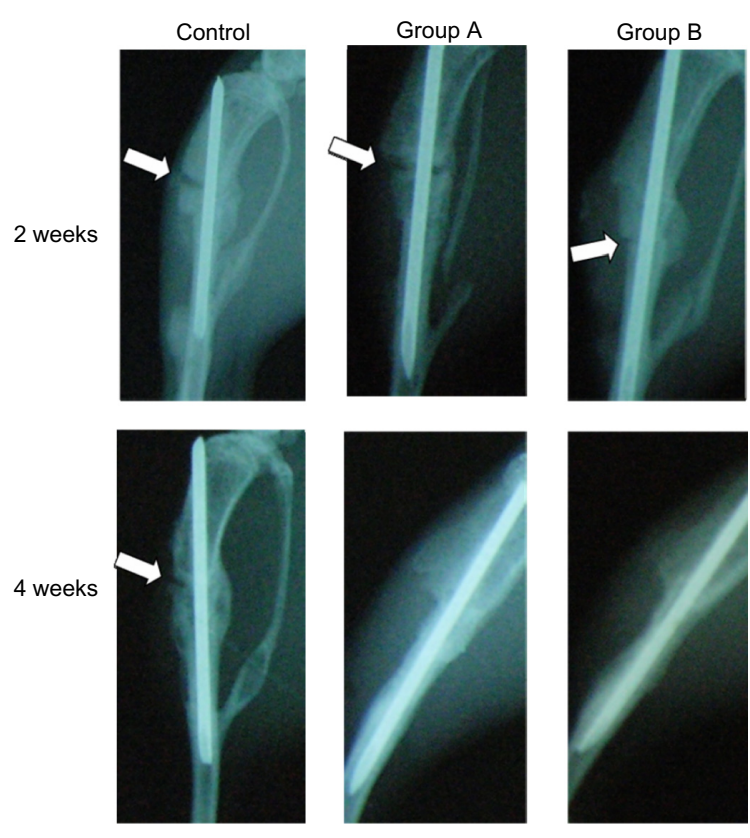

Figure 4 Radiography of BALB/c mice tibias 2 and 4 weeks after implantation of $\mathrm{SIM} / \mathrm{PLGA} / \mathrm{HAp}$. The bone fragment without any implantation is denoted as the control. The white arrows indicate the bone defects (group A, 3 mg SIM/PLGA/HAp; group B, 5 mg SIM/PLGA/HAp).

Abbreviation: SIM/PLGA/HAp, simvastatin encapsulated in poly(lactic-co-glycolic acid)/hydroxyapatite microspheres. and 4 after SIM/PLGA/HAp implantation compared with the nontreated controls. An obvious gap (white arrows) was observed at the anterior tibia in the control group after 2 and 4 weeks. Group A and group B showed better treatment efficacy then the control group. At 2 weeks, gaps (white arrows) could still be observed at the anterior tibia in group A and group B, but full union with the callus around the graft bone was observed at 4 weeks. Six weeks later (data not shown), all samples were shown to have a well healed gap.

\section{Histologic analysis and immunostaining of bone tissue}

Histologic results are shown in Figure 5. The necrotic bone graft was observed at weeks 2 and 4. Based on analysis of the micrographs, groups A and B appeared to have better callus formation around the necrotic bone graft. However, scattered callus around the grafted bone could be observed in all samples at 2 weeks. At 4 weeks after surgery, the calluses bridged the fracture area around the grafted bones. We further used Image-Pro Plus 5.0 software (Media Cybernetics Inc.; Rockville, MD, USA) to quantify matrix formation in the callus of histologic sections stained with hematoxylin-eosin. The percentages of bone matrix in groups A and B were significantly better than that in the control group at 2 weeks
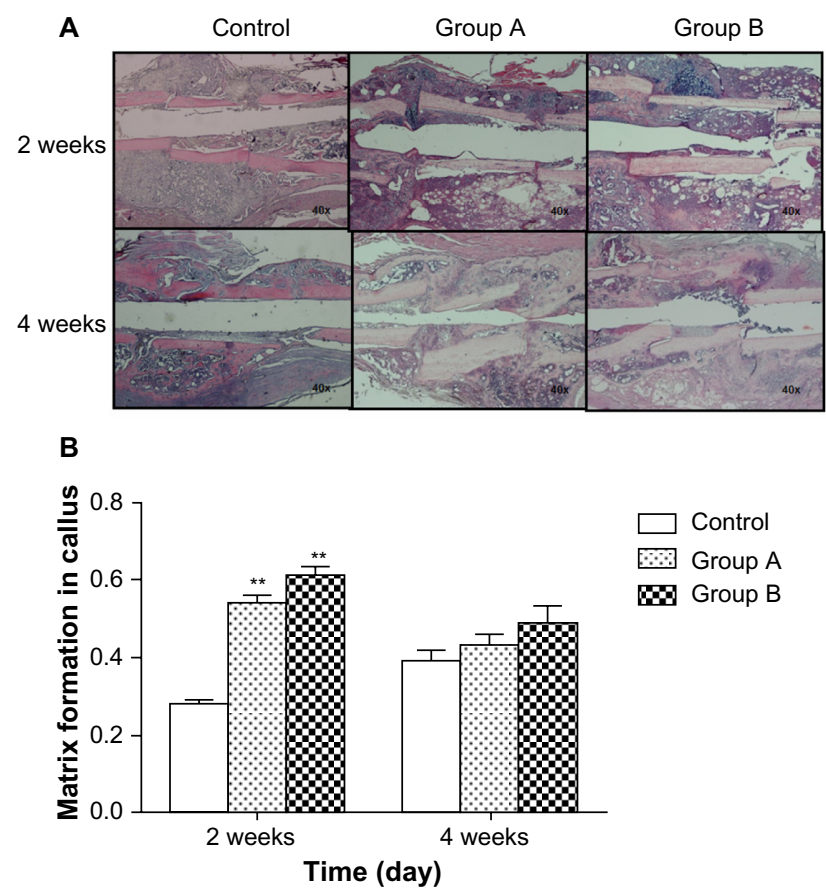

Figure 5 Histologic study of necrotic bone at 2 and 4 weeks after implantation of two doses of SIM/PLGA/HAp. (A) Hematoxylin-eosin staining and (B) quantification of matrix formation in the callus by Image-Pro Plus (group A, $3 \mathrm{mg}$ SIM/PLGA/HAp; group $B, 5 \mathrm{mg}$ SIM/PLGA/HAp). **P $<0.01$ compared with control.

Abbreviation: SIM/PLGA/HAp, simvastatin encapsulated in poly(lactic-co-glycolic acid)/hydroxyapatite microspheres. 
(Figure 5B). However, there were no significant differences between the three groups after quantification at 4 weeks.

Neovascularization is an important indicator of new bone formation. We used von Willebrand factor staining to evaluate new blood vessel formation in necrotic bone. Formation and growth of new blood vessels after treatment with $\mathrm{SIM} / \mathrm{PLGA} / \mathrm{HAp}$ is indicated by brown von Willebrand factor staining. Figure 6 shows that groups A and B had more scattered, brown-colored epithelial tissues in the graft bone than did the control group at 2 and 4 weeks. Further, quantification of new blood vessels in the total graft bone area showed that numbers in groups A and B were significantly different from that in the control at 2 and 4 weeks.

Neovascularization represents new vessel ingrowth, and this process can recruit more bone marrow stromal cells to facilitate bone substitution and improve bone formation. Figure 7 shows significantly enhanced cell ingrowth into the graft bone in groups A and B compared with the control at 2 weeks. However, only group B showed enhanced cell ingrowth into the necrotic bone at 4 weeks.

\section{Discussion}

In this study, we developed a PLGA-microsphere drug carrier system to release simvastatin in a sustainable manner

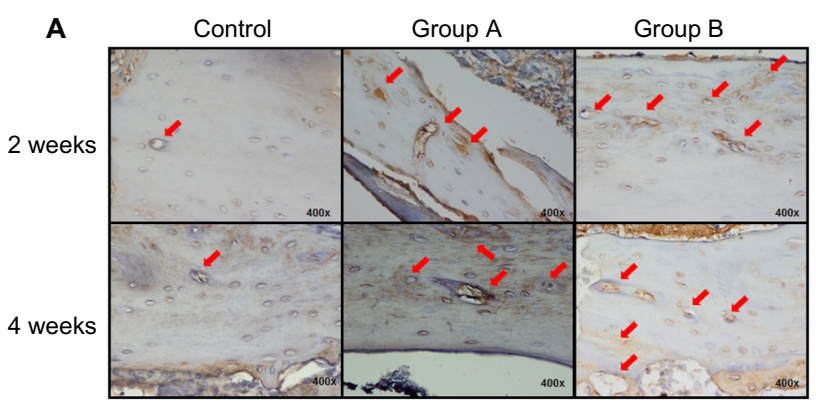

B

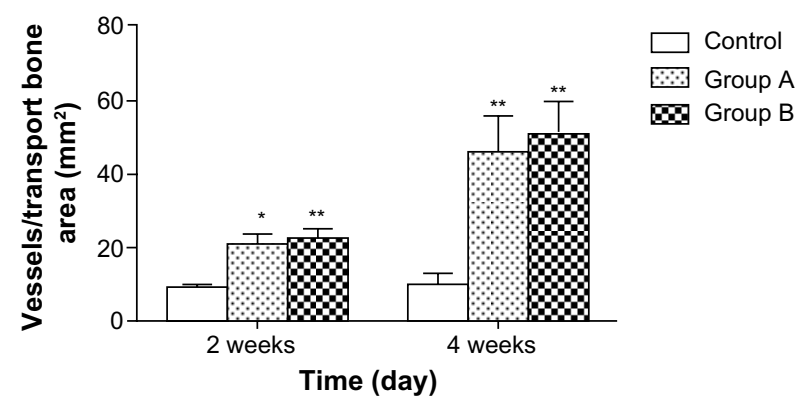

Figure 6 Histologic study of necrotic bone at 2 and 4 weeks after implantation of two doses of SIM/PLGA/HAp. (A) von Willebrand factor immunohistochemical staining and (B) quantification by calculating the vessel number in the transplanted necrotic bone (group A, $3 \mathrm{mg}$ SIM/PLGA/HAp; group B, $5 \mathrm{mg}$ SIM/PLGA/HAp). $* P<0.05 ; * * P<0.01$ compared with control.

Abbreviation: SIM/PLGA/HAp, simvastatin encapsulated in poly(lactic-co-glycolic acid)/hydroxyapatite microspheres.
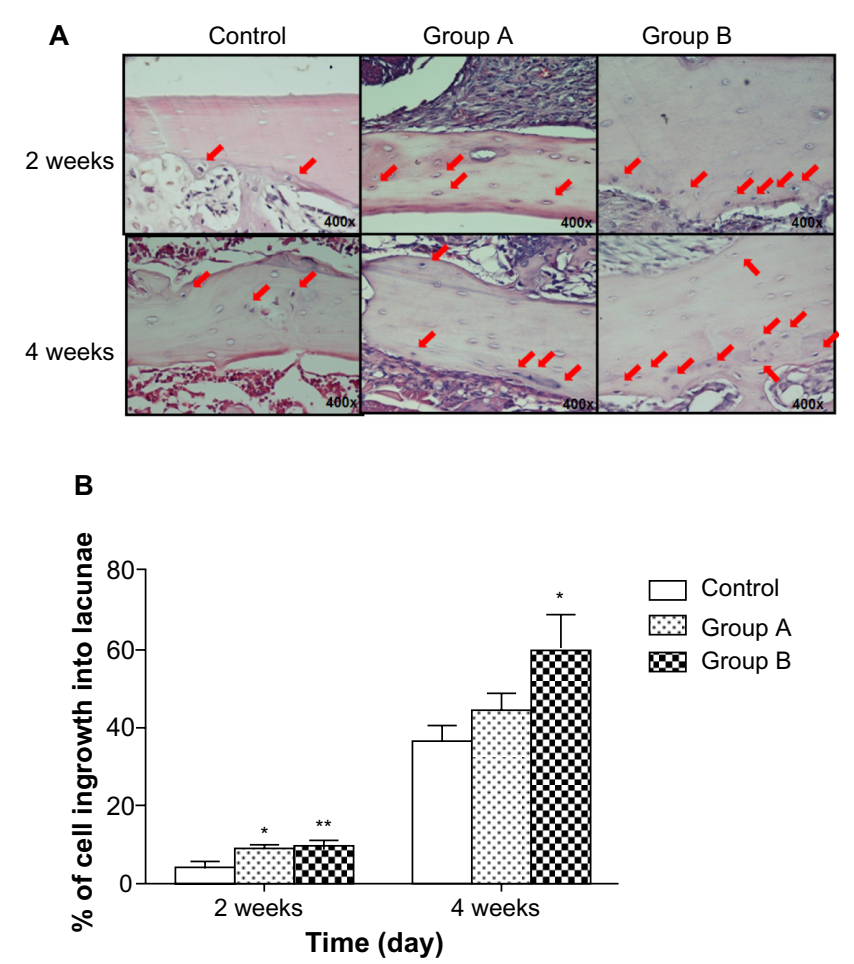

Figure 7 Histologic study of necrotic bone at 2 and 4 weeks after implantation of two doses of SIM/PLGA/HAp. (A) Hematoxylin-eosin staining and (B) quantification of cell ingrowth into the transplanted bone (group A, $3 \mathrm{mg}$ SIM/PLGA/HAp; group $B$, $5 \mathrm{mg}$ SIM/PLGA/HAp). $* P<0.05$; **P $<0.01$ compared with control.

Abbreviation: SIM/PLGA/HAp, simvastatin encapsulated in poly(lactic-co-glycolic acid)/hydroxyapatite microspheres.

and significantly enhance osteogenesis in bone marrow stromal cell cultures. In vivo, we found that SIM/PLGA/ HAp transplantation enhanced the healing process and new bone formation in a gap fracture bridged with necrotic bone in mice. Further, the controlled release of simvastatin from SIM/PLGA/HAp promoted neovascularization and cell ingrowth in the grafted necrotic bone. This newly developed SIM/PLGA/HAp formulation may be used as an osteoinductive drug to enhance bone healing.

PLGA has been widely used as a drug delivery system because of its biocompatibility and biodegradability. The main advantage of using PLGA as a carrier is that the release profile can be determined by different parameters, such as molecular weight and the ratio of lactide to glycolide. However, its main problem is an initial burst release which may exceed the toxicity limit. In this study, an initial burst release of simvastatin $(0.53 \mu \mathrm{g})$ on the first day was observed (Figure 2A). This burst release may result from the surfaceadsorbed open acid form of simvastatin used, which is partially hydrophilic ${ }^{32}$ and attaches easily to the surface of PLGA microspheres in $\mathrm{w} / \mathrm{o} / \mathrm{w}$ double emulsion. However, the amounts of simvastatin released on the first day and each subsequent 13 days were within the nontoxic therapeutic range for osteogenesis. The controlled-release PLGA system 
developed in this study is suitable for carrying simvastatin to enhance osteogenesis. Nevertheless, according to our previous findings, adjusting the ratio of PLGA and amount of supplementary HAp and changing the surfactant may eliminate burst release from SIM/PLGA/HAp. ${ }^{28}$

Since Mundy et al first reported that simvastatin enhances bone formation, it has been known that the statin dose plays a crucial role in bone formation in vivo. ${ }^{9}$ Several other studies have shown that the dose of simvastatin modulates the ability of the drug to increase bone volume. ${ }^{9,16,17}$ Our previous study showed that simvastatin $20 \mathrm{mg} / \mathrm{kg}$ /day enhances bone formation by increasing osteoblast numbers and osteogenic protein expression in ovariectomized rats. ${ }^{16}$ Controversial effects of simvastatin on bone formation have also been reported. ${ }^{15,33}$ Maritz et al indicated that oral administration of high-dose simvastatin $(20 \mathrm{mg} / \mathrm{kg} /$ day $)$ increases bone formation and resorption, while low-dose simvastatin ( $1 \mathrm{mg} / \mathrm{kg} /$ day $)$ decreases bone formation and increases bone resorption in rats. ${ }^{15}$ In one clinical study, simvastatin $40 \mathrm{mg}$ /day for one year significantly increased bone mineral density at the lumbar spine and femoral neck. ${ }^{34}$ Pasco et al also reported a $60 \%$ reduction in fracture risk in patients treated with statins. ${ }^{35}$ However, no dramatic change in bone mineral density was found in a one-year prospective clinical study of treatment with simvastatin $20 \mathrm{mg} / \mathrm{day} .{ }^{36}$ The conflicting results of animal and clinical studies suggest that orally administered statins may be degraded in the liver, so little of the drug is available to accumulate in bone. However, increasing the statin dose to overcome hepatic degradation may also have side effects, including myotoxicity, liver failure, and kidney failure. ${ }^{37-39}$ Subcutaneous injection of simvastatin has no significant effect on bone formation, suggesting that circulating simvastatin levels might peak and then decrease rapidly. ${ }^{23}$ These earlier reports indicated that systemic administration of simvastatin might not have the expected effect on bone formation. Accordingly, local administration was considered as a way to deliver simvastatin directly in therapeutic concentrations for bone formation.

Local administration can bypass hepatic degradation of statins to achieve therapeutic concentrations in bone and avoid the side effects caused by systemic administration. Various studies have investigated local delivery of statins to increase bone healing and reported that statins have local beneficial effects. ${ }^{5,19-26}$ However, some studies showed adverse effects. ${ }^{21,24,27}$ Thylin et al and Stein et al reported that local application of simvastatin $2.2 \mathrm{mg}$ caused inflammation in soft tissue in a rat calvarial bone defect model and in mandible bone. ${ }^{21,24}$ Nyan et al reported that local administration of simvastatin $1 \mathrm{mg}$ in combination with alpha-tricalcium phosphate delayed bone union. ${ }^{27}$ The inflammatory effect and delayed bone union was caused by a high dose or burst release of the locally applied statin. The results of this study show that daily release of simvastatin in the range of $0.02-0.53 \mu \mathrm{g} /$ day enhances bone healing in vivo and does not cause an obvious inflammatory response, as demonstrated by a histologic study (Figure 5A). Cytotoxicity to the liver, muscle, and kidneys was investigated by measuring serum alanine aminotransferase, aspartate aminotransferase, and creatine phosphokinase levels, and the results indicated that SIM/PLGA/HAp does not have toxic systemic effects (Table 1). Previous in vitro studies have indicated that statins in the dose range of 0.01-5 $\mu \mathrm{M}$ increase expression of osteogenic marker genes, such as RUNX-2, BMP-2, osteocalcin, osteopontin, and alkaline phosphatase, in cultured osteoblastic cells and bone marrow-derived cells. ${ }^{9-15}$ In this study, the amount of simvastatin released daily was within the concentrations range of $0.02-0.53 \mu \mathrm{g} /$ day $(0.1-5 \mu \mathrm{M} /$ day $)$, which significantly stimulated osteogenic gene expression of RUNX-2, BMP-2, alkaline phosphatase, and osteocalcin (Figure 3A-D) and final mineralization (Figure 3E) in cultured D1 cells. This result indicates that this newly developed SIM/PLGA/HAp system releases a nontoxic therapeutic dose of simvastatin for osteogenesis in bone marrow stromal cells.

In our animal study, callus formation around the grafted bone in the $3 \mathrm{mg}$ and $5 \mathrm{mg}$ SIM/PLGA/HAp groups was significantly greater than that in the control group at 2 weeks after grafting (Figure 5). This finding indicates that the mass effect of the callus may contribute to initial stabilization of the graft and thus improve new bone formation. Further, the histologic results show that significant neovascularization was achieved in both the $3 \mathrm{mg}$ and $5 \mathrm{mg} \mathrm{SIM/PLGA}$ HAp groups at 2 and 4 weeks after grafting, but was rarely observed in the control group (Figure 6). This suggests that the simvastatin released not only enhanced osteogenesis but also significantly stimulated neovascularization. Most importantly, significantly greater cell ingrowth was found in the grafted necrotic bone in the simvastatin-treated groups compared with the control group, suggesting that simvastatinstimulated neovascularization might help transport stem cells into necrotic bone to facilitate regeneration of bone.

\section{Conclusion}

In conclusion, the SIM/PLGA/HAp system developed in this study has controlled-release properties that not only enhance callus formation during initiation of fracture healing but also increase neovascularization and cell ingrowth in grafted bone. We suggest that the SIM/PLGA/HAp system may be used as an osteoinductive agent to treat osteonecrosis or in combination with an osteoconductive scaffold to treat severe bone defects. 


\section{Acknowledgment}

The authors gratefully acknowledge the support of this research by grants from the Ministry of Economic Affairs, National Science Council and Kaohsiung Medical University Hospital in Taiwan (99-EC-17-A-17- S1-041, 100-EC-17A-19-S1-176, NSC 99-2314-B-037-061-MY3,KMUH1011I01, KMUH100-0R37).

\section{Disclosure}

The authors declare no conflicts of interest in this work.

\section{References}

1. Yelin EH, Felts WR. A summary of the impact of musculoskeletal conditions in the United States. Arthritis Rheum. 1990;33:750-755.

2. Heckman JD, Sarasohn-Kahn J. The economics of treating tibia fractures. The cost of delayed unions. Bull Hosp Jt Dis. 1997;56:63-72.

3. Bax BE, Wozney JM, Ashhurst DE. Bone morphogenetic protein-2 increases the rate of callus formation after fracture of the rabbit tibia. Calcif Tissue Int. 1999;65:83-89.

4. Kandziora F, Bail H, Schmidmaier G, et al. Bone morphogenetic protein-2 application by a poly(D,L-lactide)-coated interbody cage: in vivo results of a new carrier for growth factors. J Neurosurg. 2002;97: $40-48$.

5. Garrison KR, Donell S, Ryder J, et al. Clinical effectiveness and costeffectiveness of bone morphogenetic proteins in the non-healing of fractures and spinal fusion: a systematic review. Health Technol Assess. 2007;11:1-150, iii-iv.

6. Shields LB, Raque GH, Glassman SD, et al. Adverse effects associated with high-dose recombinant human bone morphogenetic protein-2 use in anterior cervical spine fusion. Spine (Phila Pa 1976). 2006;31: $542-547$.

7. Corsini A, Bellosta S, Baetta R, Fumagalli R, Paoletti R, Bernini F. New insights into the pharmacodynamic and pharmacokinetic properties of statins. Pharmacol Ther. 1999;84:413-428.

8. Schachter M. Chemical, pharmacokinetic and pharmacodynamic properties of statins: an update. Fundam Clin Pharmacol. 2005;19: $117-125$.

9. Mundy G, Garrett R, Harris S, et al. Stimulation of bone formation in vitro and in rodents by statins. Science. 1999;286:1946-1949.

10. Maeda T, Matsunuma A, Kawane T, Horiuchi N. Simvastatin promotes osteoblast differentiation and mineralization in MC3T3-E1 cells. Biochem Biophys Res Commun. 2001;280:874-877.

11. Song C, Guo Z, Ma Q, et al. Simvastatin induces osteoblastic differentiation and inhibits adipocytic differentiation in mouse bone marrow stromal cells. Biochem Biophys Res Commun. 2003;308:458-462.

12. Hwang R, Lee EJ, Kim MH, et al. Calcyclin, a Ca2+ ion-binding protein, contributes to the anabolic effects of simvastatin on bone. J Biol Chem. 2004;279:21239-21247.

13. Baek KH, Lee WY, Oh KW, et al. The effect of simvastatin on the proliferation and differentiation of human bone marrow stromal cells. J Korean Med Sci. 2005;20:438-444.

14. Solomon DH, Finkelstein JS, Wang PS, Avorn J. Statin lipid-lowering drugs and bone mineral density. Pharmacoepidemiol Drug Saf. 2005;14: 219-226.

15. Maritz FJ, Conradie MM, Hulley PA, Gopal R, Hough S. Effect of statins on bone mineral density and bone histomorphometry in rodents. Arterioscler Thromb Vasc Biol. 2001;21:1636-1641.

16. Ho ML, Chen YH, Liao HJ, et al. Simvastatin increases osteoblasts and osteogenic proteins in ovariectomized rats. Eur J Clin Invest. 2009;39: 296-303.

17. Skoglund B, Forslund C, Aspenberg P. Simvastatin improves fracture healing in mice. J Bone Miner Res. 2002;17:2004-2008.
18. van Staa TP, Wegman S, de Vries F, Leufkens B, Cooper C. Use of statins and risk of fractures. JAMA. 2001;285:1850-1855.

19. Garrett IR, Gutierrez GE, Rossini G, et al. Locally delivered lovastatin nanoparticles enhance fracture healing in rats. J Orthop Res. 2007;25: 1351-1357.

20. Lee Y, Schmid MJ, Marx DB, et al. The effect of local simvastatin delivery strategies on mandibular bone formation in vivo. Biomaterials. 2008;29:1940-1949.

21. Stein D, LeeY, Schmid MJ, et al. Local simvastatin effects on mandibular bone growth and inflammation. J Periodontol. 2005;76:1861-1870.

22. Wang JW, Xu SW, Yang DS, Lv RK. Locally applied simvastatin promotes fracture healing in ovariectomized rat. Osteoporosis Int. 2007;18:1641-1650.

23. Skoglund B, Aspenberg P. Locally applied simvastatin improves fracture healing in mice. BMC Musculoskelet Disord. 2007;8:98.

24. Thylin MR, McConnell JC, Schmid MJ, et al. Effects of simvastatin gels on murine calvarial bone. J Periodontol. 2002;73:1141-1148.

25. Mukozawa A, Ueki K, Marukawa K, Okabe K, Moroi A, Nakagawa K. Bone healing of critical-sized nasal defects in rabbits by statins in two different carriers. Clin Oral Implants Res. 2011;22:1327-1335.

26. Ezirganli S, Kazancioglu HO, Mihmanli A, Aydin MS, Sharifov R, Alkan A. The effect of local simvastatin application on critical size defects in the diabetic rats. Clin Oral Implants Res. April 21, 2013. [Epub ahead of print.]

27. Nyan M, Sato D, Oda M, et al. Bone formation with the combination of simvastatin and calcium sulfate in critical-sized rat calvarial defect. J Pharmacol Sci. 2007;104:384-386.

28. Ho ML, Fu YC, Wang GJ, et al. Controlled release carrier of BSA made by $\mathrm{w} / \mathrm{o} / \mathrm{w}$ emulsion method containing PLGA and hydroxyapatite. J Control Release. 2008;128:142-148.

29. Wang CK, Ho ML, Wang GJ, et al. Controlled-release of rhBMP-2 carriers in the regeneration of osteonecrotic bone. Biomaterials. 2009;30: $4178-4186$

30. Keyomarsi K, Sandoval L, Band V, Pardee AB. Synchronization of tumor and normal cells from G1 to multiple cell cycles by lovastatin. Cancer Res. 1991;51:3602-3609.

31. Cui Q, Wang GJ, Balian G. Steroid-induced adipogenesis in a pluripotential cell line from bone marrow. J Bone Joint Surg Am. 1997;79: 1054-1063.

32. Serajuddin AT, Ranadive SA, Mahoney EM. Relative lipophilicities, solubilities, and structure-pharmacological considerations of 3-hydroxy3-methylglutaryl-coenzyme A (HMG-CoA) reductase inhibitors pravastatin, lovastatin, mevastatin, and simvastatin. J Pharm Sci. 1991;80: 830-834.

33. Chissas D, Stamatopoulos G, Verettas D, et al. Can low doses of simvastatin enhance fracture healing? An experimental study in rabbits. Injury. 2010;41:687-692.

34. Montagnani A, Gonnelli S, Cepollaro C, et al. Effect of simvastatin treatment on bone mineral density and bone turnover in hypercholesterolemic postmenopausal women: a 1-year longitudinal study. Bone. 2003;32:427-433

35. Pasco JA, Kotowicz MA, Henry MJ, Sanders KM, Nicholson GC; Geelong Osteoporosis Study. Statin use, bone mineral density, and fracture risk: Geelong Osteoporosis Study. Arch Intern Med. 2002;162:537-540.

36. Tikiz C, Tikiz H, Taneli F, Gumuser G, Tuzun C. Effects of simvastatin on bone mineral density and remodeling parameters in postmenopausal osteopenic subjects: 1-year follow-up study. Clin Rheumatol. 2005;24: $447-452$.

37. Fuentes I, Aguilera C. Myopathy secondary to the treatment with inhibitors of HMG-CoA reductase. Med Clin (Barc). 1998;111:700. Spanish.

38. Duell PB, Connor WE, Illingworth DR. Rhabdomyolysis after taking atorvastatin with gemfibrozil. Am J Cardiol. 1998;81:368-369.

39. Jacobson RH, Wang P, Glueck CJ. Myositis and rhabdomyolysis associated with concurrent use of simvastatin and nefazodone. JAMA. 1997;277:296-297. 
International Journal of Nanomedicine

Dovepress

\section{Publish your work in this journal}

The International Journal of Nanomedicine is an international, peerreviewed journal focusing on the application of nanotechnology in diagnostics, therapeutics, and drug delivery systems throughou the biomedical field. This journal is indexed on PubMed Central, MedLine, CAS, SciSearch ${ }^{\circledR}$, Current Contents ${ }^{\circledR} /$ Clinical Medicine,
Journal Citation Reports/Science Edition, EMBase, Scopus and the Elsevier Bibliographic databases. The manuscript management system is completely online and includes a very quick and fair peer-review system, which is all easy to use. Visit http://www.dovepress.com/ testimonials.php to read real quotes from published authors.

Submit your manuscript here: http://www.dovepress.com/international-journal-of-nanomedicine-journal 